\title{
CONCEPTUALIZATION OF HISTORICAL TIME IN POST KEYNESIAN ECONOMICS
}

\section{Zdeněk Chytil, Lukáš Máslo*}

\begin{abstract}
The paper deals with a problem of conceptualization of historical time in Post Keynesian models. The authors introduce a new notion that they call hysteretic persistence, which they see as essential because such a phenomenon as path-dependence in the short-run equilibrium cannot be described by the existing of notions of hysteresis and persistence. In the field of system (ir)reversibility, drawing upon their previous research (Chytil, Máslo, 2014, 2015), the authors introduce a new notion of general reversibility, which they justify on the account that such phenomena as a shock - countershock sequence in both hysteretic-persistent and hysteretic systems cannot be described by either of Setterfield's (2008) notions of super-reversibility and irreversibility. Questioning Setterfield's (1998b, 1995) only too general dichotomy of lower/higher level of historical time, the authors rather suggest a characterization of historical time based on 6 attributes of "high-level" historical time based on the criteria of path-(in)dependence of equilibrium and (ir)reversibility. The suggested attributes underlie the authors' conceptualization scale which enables an assessment of a degree of "historicity" of any system. Finally, a practical application of the concept of hysteretic persistence is demonstrated on a case of Lavoie's PKA model (Lavoie, 2006) affected by a transitory demand shock. Setting the hysteretic persistence of Lavoie's PKA model into the conceptualization scale, the authors draw conclusions for a degree of "historicity" of this system.
\end{abstract}

Keywords: historical time, logical time, irreversibility, path-dependence, hysteresis, persistence, New Consensus

JEL Classification: B4, B5, C6, E12, E5

\section{Introduction}

Post Keynesian economics takes a critical standpoint towards fundamental propositions of the neoclassical mainstream. At the methodological level, Post Keynesians attack the alleged irrelevance of realistic assumptions (e.g. Chick, 2004, p. 4; Jespersen, 2009, Chapter 2, pp. 53-109) and promote the critical-realistic methodology of semi-closed or conditionalclosed systems (e.g. Jespersen, 2009, Chapter 5, pp. 132-154; Setterfield, 1997, p. 68ff), in opposition to the axiomatic-deductive approach of neoclassical closed systems. In the theory, Post Keynesians put in question the feasibility of the general-equilibrium concept as a starting point of macroeconomic analysis (e.g. Setterfield, 2005; Setterfield, 1995, pp. 11-12; Kaldor, 1972, pp. 1237-1244) and they suggest to rather build macroeconomics on a paradigm of path-dependence, which perceives time as less logical than historical

* Zdeněk Chytil, Department of Economics, Faculty of Economics, University of Economics in Prague, Prague, Czech Republic (chytil@vse.cz);

Lukáš Máslo, Department of Economics, Faculty of Economics, University of Economics in Prague, Prague, Czech Republic (xmas114@vse.cz). 
(e.g. Setterfield, 1997, p. 56ff; 1995, p. 11ff; Jespersen, 2009, Chapter 6, pp. 155-179). "NonEquilibrium Economics" reaches back to the 1930s, at least, when Nicholas Kaldor begged up the basic questions about the fundamental postulates of the neoclassical concept of traditional equilibrium in his classic paper "A Classificatory Note on the Determinateness of Equilibrium" (Kaldor, 1934). An economist who questioned the general equilibrium theory probably most thoroughly was John Maynard Keynes who implied even by the name of his historical work "General Theory of Employment, Interest and Money" (Keynes, 1936) that general equilibrium is just a special case ${ }^{1}$. In the traditional-equilibrium concept, any deviation of the system out of its equilibrium results in a restore of this equilibrium configuration, in the end, without any additional exogenous intervention being necessary - the equilibrium has a nature of a center of gravity (Setterfield, 1997, pp. 54, 62, 65) here to which the system is attracted automatically.

In this paper, our primary goal is threefold. First, drawing upon our previous efforts in this direction made in Chytil, Máslo (2014, 2015), we want to provide a redefinition of the term "reversibility" to escape the inconsistencies and ambiguities resulting from terminology in Setterfield (2008). For this purpose, we will present our notion of general reversibility whereby we will reject the self-contradictory meaning of super-reversibility in Setterfield (2008) and, instead, redefine the latter as a special case of the former. Second, we want to present and introduce our notion of hysteretic persistence that, as we argue, captures a phenomenon which cannot be described in terms of either hysteresis or persistence, such as the last mentioned terms are used in Setterfield (1998a, 2008), Katzner (1999, 1993) and Franz (1990). Third, we want to use the two mentioned characteristics of a system as a base ground to infer 6 attributes of historical time that we will suggest to make use of as criteria to assess a degree of a system's "historicity" much better than a low-level/highlevel historical time dichotomy in Setterfield (1998b, 1995). These 6 attributes will serve us to suggest a "conceptualization scale" to arrange some basic systems according to their respective "historicity", namely persistence, hysteretic persistence, unit-root hysteresis, zero-root hysteresis, "Lavoie's" hysteresis and Setterfield's hysteresis.

If the logical-time framework implies that all paths lead to an exogenously determined equilibrium, which is independent of these paths, then the historical-time framework implies endogenization of such an equilibrium and, in effect, dependence of such an equilibrium's position on the particular path chosen to reach it. There are several specific conceptualizations (Setterfield, 1995, p. 24) of this general principle, though, mutually varied according to their respective adherence to the fundamental attributes of historical time. In extreme, we can distinguish a complete absence of any attributes of historical time on one pole - a concept of traditional-equilibrium in the logical-time framework - from a complete and full "historicity" on the other pole - in which case the reality is treated in the totality of all its particular aspects. The perfect "historicity" may probably be best characterized by Heracleitos' proposition that you will not enter the same river twice. Between these two extreme poles, a broad grey zone can be found where different degrees of conceptualizations of historical time can be distinguished, with respect to the criterion of how far the particular conceptualization captures the fundamental attributes of "high-level" historical time, i.e. 1) path-dependence in the short-run equilibrium, 2) path-dependence in the long-run equilibrium, 3) deep endogeneity of parameters, 4) adjustment asymmetries (Setterfield's hysteresis), 5) irreversibility, 6) irrevocability.

1 For our interpretation of Keynes's underemployment equilibrium see Máslo, Chytil (2015). 
The Section 2 provides a general introduction into the notion of historical time. The Section 3 focuses on particular conceptualizations of historical time and on placing these into the conceptualization scale. In this section, we present our notions of hysteretic persistence and general reversibility, as well as our conceptualization scale. Finally, in the Section 4, we present a practical application of our concept of hysteretic persistence on the applied case of Lavoie's PKA model (three-equation NC model of monetary policy incorporating path-dependence in the natural rate of growth) affected by a transitory demand shock. Setting the hysteretic persistence of Lavoie's PKA model into our conceptualization scale, we draw some conclusions about a degree of this system's "historicity".

\section{The Notion of Historical Time}

\subsection{The Cobweb Model: Logical Time}

Joan Robinson characterizes the logical-time paradigm as follows: "In a model depicting equilibrium positions there is no causation. It consists of a closed circle of simultaneous equations. The value of each element is entailed by the values of the rest. At any moment in logical time, the past is determined just as much as the future [...]" (Robinson in Setterfield, 1995, p. 4). The notion of logical time may be illustrated by means of a traditionalequilibrium model of a partial equilibrium, the cobweb model. A price is determined

$$
P_{t+1}=f_{1}\left(f_{2}\left(P_{t}\right)\right)
$$

where the quantity is

$$
Q_{t+1}=f_{2}\left(f_{1}\left(Q_{t}\right)\right) \text {. }
$$

If we express the equations of supply and demand generally as

$$
\begin{aligned}
\text { S: } Q & =a P \\
\text { D: } Q & =b-c P \\
P & =b / c-(1 / c) \cdot Q,
\end{aligned}
$$

then the equation

$$
P_{t+1}=f_{1}\left(f_{2}\left(P_{t}\right)\right)
$$

can be expressed in general terms as

$$
P_{t+1}=b / c-(a / c) \cdot P_{t},
$$

where the condition of equilibrium $P_{t+1}=P_{t}$ implies

and so

$$
P^{*}=b / c-(a / c) \cdot P^{*},
$$

$$
P^{*}=b /(a+c) .
$$

The equilibrium is obviously determined in terms of parameters $a, b, c$. Regardless of the precise initial disequilibrium, the system always (assumed the stable equilibrium) converges 
to the identical equilibrium configuration: this configuration is path-independent as it does not depend on the causality of any particular path. If, for example

$$
\begin{aligned}
& \text { S: } Q=2 P \\
& \text { D: } Q=20-4 P,
\end{aligned}
$$

or

$$
P=5-1 / 4 Q
$$

then $Q^{*}=6.667$ a $P^{*}=3.333$. Let us choose the initial supply price $P_{S 1}=7$. Then, the process of convergence may be visualized in a following way:

\section{Figure 1 | Logical Time in the Cobweb Model}

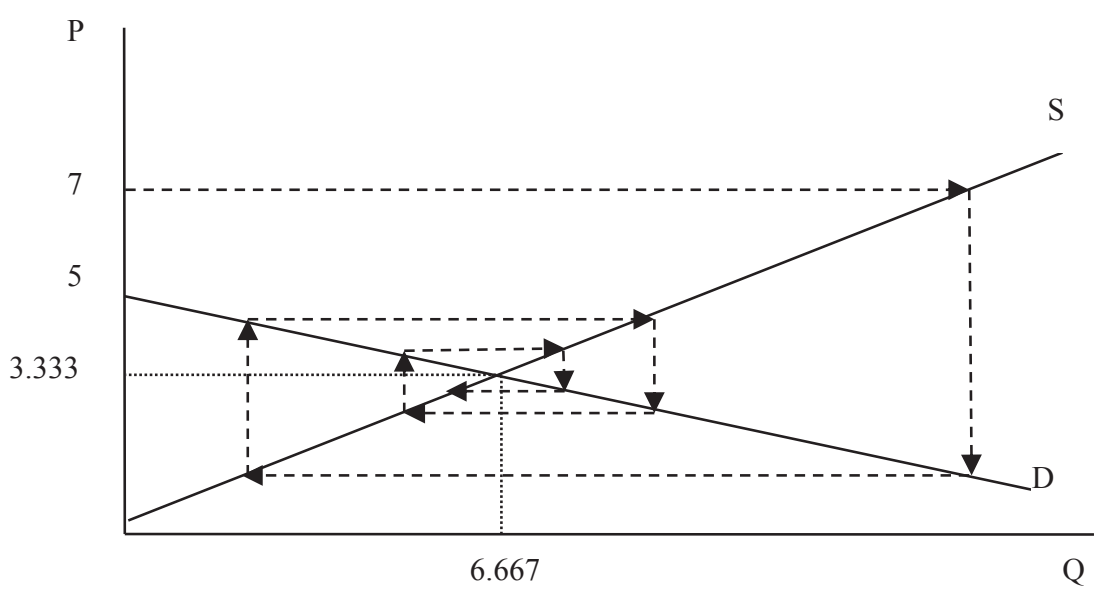

Source: authors' own scheme

\subsection{The Cobweb Model: Historical Time}

Let us assume a path-dependent amendment of the above described cobweb model, for example through functional dependence of the value of the parameter $b$ in the period $t$ on the value of the price in the previous period $t-1$ :

$$
b_{t}=\psi\left(P_{t-1}\right) .
$$

Then, the equation which characterizes the system can be written in the following form

$$
P_{t+1}=b_{t+1} / c-(a / c) \cdot P_{t}
$$

or, interchangeably for $Q$

$$
Q_{t+1}=a \cdot b_{t+1} / c-(a / c) \cdot Q_{t},
$$

after substitution for $b$ 


$$
P_{t+1}=\psi\left(P_{t}\right) / c-(a / c) \cdot P_{t} .
$$

or interchangeably for Q

$$
Q_{t+1}=a \cdot \psi\left(P_{t}\right) / c-(a / c) \cdot Q_{t} .
$$

Let us assume the functional dependence $\psi\left(P_{t}\right)$ is a mere multiplication

$$
\psi\left(P_{t}\right)=d \cdot P_{t},
$$

which implies

$$
b_{t}=d \cdot P_{t-1} .
$$

In other words, the value of a parameter $b$ (which co-determines the position of a demand curve) is functionally dependent on the price in the previous period. Then, taking the equilibrium price into account

$$
P^{*}=b /(a+c),
$$

we find out that - down to the path-dependence in the parameter $b$ expressed by this parameter's functional dependency on the price of the previous period - the equilibrium price is defined by the formula

$$
P_{t}^{*}=d \cdot P_{t-1} /(a+c) .
$$

That is: the equilibrium price in a period $\mathrm{t}$ is path-dependent itself on the current price in a period $(t-1)$, via the path-dependence in the parameter $b$. In effect, we can see that the equilibrium price $P^{*}$ is changing in the course of time by virtue of the changes in the parameter $b$ which, in turn, changes its own value by virtue of its dependence on the current $P$ price of the previous period.

\subsection{Two Levels of Historical Time}

At several places, Setterfield stresses the fact that you cannot have a model which captures all the characteristic features of historical time (Setterfield, 1997, p. 60; 1996, p. 143; 1995, pp. 2, 26). Jespersen follows the same line of argument stating that a model (or, in Jespersen's terms, World 2 or analytical level) can never present a projection of reality at a scale of 1:1 (Jespersen, 2014, p. 70). Hayek came to an analogical conclusion when he summed up that "a model always represents only some but not all the features of the original (so that an exact replica of a machine could not appropriately be called a model)" (Hayek, 1955, p. 221). Historical time in the authentic meaning of the word thus reflects the unrepeatable uniqueness of a moment in the whole totality of phenomena and exhibits irrevocability, as a result (Setterfield, 1995, pp. 5-6). The ultimate irrevocability of any process is always the passed time. Even if the initial configuration of all thinkable variables were renewable, the passed time cannot be brought back. You cannot enter the same river twice. In many economic processes, such a strict conception is not necessary for analytical purposes, though, and it would not even be reasonable, either. Setterfield makes use of a distinction between "high-level" historical time and "low-level" historical time to capture a difference of a theoretical from a practical level of the concept of historical time. 
The "high-level" historical time is a theoretically rigorous and pure expression of the irrevocable feature of any real process and it is a concept "that embodies a more abstract and philosophical conception of the nature of decisions, actions and outcomes located in time", while the "low-level" historical time is a model approximation "embodied in specific concepts of path dependency (such as cumulative causation) that can be used in practical modelling exercises." (Setterfield, 1998b, p. 534). Inferring from this indirect definition, we suggest the following explicit definition of historical time: "Historical time is a methodological concept characterized by a systemic feature of path-dependence in the equilibrium value."

\section{Conceptualization of Historical Time}

\subsection{Path-dependence in the Equilibrium Value}

The first two attributes of historical time that we identify here are path-dependence of the long-run and short-run equilibrium. Setterfield talks about persistence when a system exhibits path-dependence in the short-run (potential) equilibrium only, with the long-run equilibrium being path-independent (Setterfield, 1998a, p. 290). However, at a different place, he defines persistence unambiguously as a process of convergence of a traditionalequilibrist system to its predetermined equilibrium after the system has been deflected from its equilibrium previously (Setterfield, 2008, p. 30). This indicates inconsistency. Katzner, for example, uses the term persistence in the latter meaning, as a synonym for the $|\alpha|<1$ category of general hysteresis (Katzner, 1999, p. 175; 1993, p. 331). The term is also understood by Franz in the same meaning (Franz, 1990, p. 120). In contrast, Amable insists on the use of the term persistence to refer to the unit/zero-root case in the system of difference/differential equations, instead of misleadingly (from Amable's viewpoint) referring to these systems as hysteretic (Amable, 1994, pp. 45-46). In this paper, we grasp persistence in the sense of Setterfield (2008). Since Setterfield juxtaposes persistence in the sense of Setterfield (2008) - to hysteresis - which he conceives in his works as path-dependence in the long-run equilibrium, consistently - and since path-dependence in the short-run (or potential) equilibrium displays the signs of both the traditional-equilibrist systems (i.e. path-independence in the long-run equilibrium) and hysteretic systems (i.e. path-dependence in the equilibrium, generally), we suggest to call this specific case by a term hysteretic persistence. In other words, our term hysteretic persistence refers to a case of path-dependence in the short-run equilibrium while Setterfield's term persistence (Setterfield, 2008) means convergence to a long-run equilibrium without any pathdependence in either the short-run or long-run equilibrium and while Setterfield's term hysteresis (Setterfield, 2008) refers to a case of path-dependence in the long-run equilibrium. Our notion of hysteretic persistence is thus not redundant because it refers a phenomenon different from both persistence and hysteresis.

With respect to path-dependence of outcomes, three types of systems may be distinguished:

a) systems exhibiting persistence,

or traditional-equilibrist systems with a unique stable equilibrium which may be characterized in the following way: 


$$
\begin{gathered}
X_{t}=X_{t}\left(X_{t-1}\right) \\
X_{t}^{*}=X^{*}
\end{gathered}
$$

Figure 2 | Persistence in a System of Traditional Equilibrium

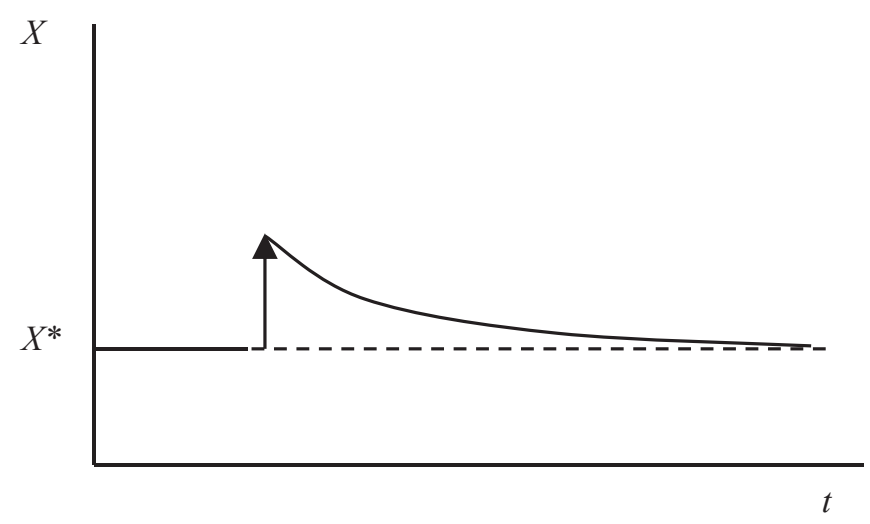

$X_{t}$

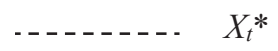

Source: authors' own scheme

b) systems exhibiting hysteretic persistence,

or systems with a path-dependent short-run (potential) equilibrium and time-invariant pathindependent long-run equilibrium:

$$
\begin{gathered}
X_{t}=X_{t}\left(X_{t-1}\right) \\
X_{t}^{*}=X_{t}^{*}\left(X_{t-1}\right) \\
\left(X_{t}^{*}\right)^{*}=\left(X^{*}\right)^{*}
\end{gathered}
$$

Figure 3 | Hysteretic Persistence

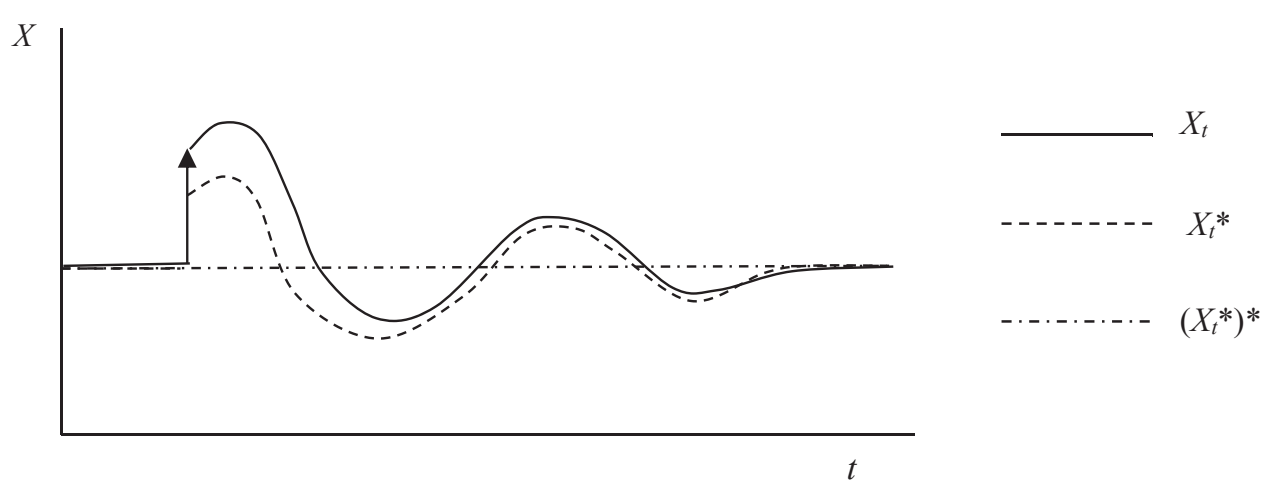

Source: authors' own scheme 
Equation (20) just wants to say that the current value of $X$ is an unspecified function of the value of $X$ from the preceding period. In opposition to it, Equation (21) expresses that the equilibrium value of $X$ in time $t$ is determined exogenously as $X^{*}$, i.e. it is pathindependent. Hysteretic persistence means that while the equilibrium value of $X$ is pathdependent in the short run (i.e. the equilibrium value of $X$ is an unspecified function of the past current value of $X$ ), it is path-independent in the long run, though. For this purpose, we distinguish between what we might refer to as a "short-run equilibrium value", $X_{t}^{*}-$ which is path-dependent in case of hysteretic persistence and which we graph by a dashed curve - and what we might refer to as a "long-run equilibrium value" $\left(X_{t}^{*}\right)^{*}$ - which is pathindependent in case of hysteretic persistence and which we graph by a dot-and-dashed line at the level which is constant.

c) systems exhibiting hysteresis,

or systems exhibiting path-dependence not only in the short-run equilibrium values but also in the long-run equilibrium values:

$$
\begin{gathered}
X_{t}=X_{t}\left(X_{t-1}\right) \\
X_{t}^{*}=X_{t}^{*}\left(X_{t-1}\right) \\
\left(X_{t}^{*}\right)^{*}=\left(X_{t}^{*}\right)^{*}\left(X_{t-1}\right)
\end{gathered}
$$

\section{Figure 4 | Hysteresis}

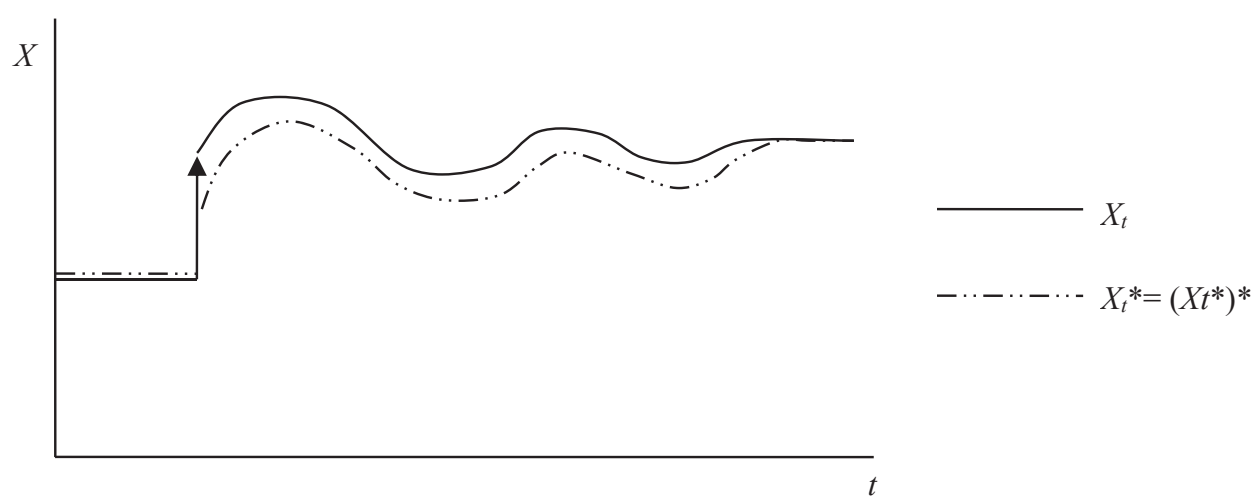

Source: authors' own scheme

\section{2 (Ir)reversibility}

With respect to the above said we distinguish dynamic systems from static systems. An example of dynamic system can be the one-equation system

$$
X_{t}=\alpha X_{t-1}+\varepsilon_{t}
$$

where $X$ is the so called "output variable" or "variable of concern", $\varepsilon$ is an exogenous direct shock and $\alpha$ is a parameter ensuring the presence of endogenous dynamics in the system. 
We call a change in the value of the parameter $\alpha$ a true indirect shock. If this system is affected by a direct shock $\varepsilon$ which is followed by a direct shock $(-\varepsilon)$ which has the same value as the initial shock but the opposite sign, then we refer to $(-\varepsilon)$ as a direct countershock. An example of a static system can be

$$
Q=-\alpha P+b
$$

however, we deal with dynamic systems in this paper, primarily, so, we do not need to keep on analysing the terminology of shocks in static systems. We define a direct shock $\varepsilon$ as a change in the value of an output variable brought about by a direct exogenous influence on this variable. We define a direct counter-shock $(-\varepsilon)$ as a change in the value of an output variable brought about by a direct exogenous influence on this variable where this influence works (if not said differently) with the same intensity but in the opposite direction than the preceding influence. A specific type of a system is the so called unit-root case where the only source of dynamics is presented by an exogenous shock and which exhibits the so called unit-root hysteresis. Unit-root hysteretic systems of a following type

$$
X_{t}=X_{t-1}+\varepsilon_{t}
$$

which lack any source of own endogenous dynamics whatsoever (Chytil, Máslo, 2014, pp. 166-167) and which show a continuum of locally stable multiple equilibria (Setterfield, 1995 , p. 10) are, then - with respect to their capability to reverse a shock by a counter-shock - super-reversible, to preserve Setterfield's term, because an application of a direct countershock of the same value and the opposite sign causes a transition between indifferent equilibria without a change in the structure of the system (Amable, 1993, pp. 129-130).

In our analysis of system (ir)reversibility, we draw upon Setterfield (2008), primarily. However, Setterfield's terminology in Setterfield (2008) but also in Setterfield (1995, 1996, 1998a) is in a desperately chaotic state which we already criticized in Chytil, Máslo (2014, 2015). The problem of Setterfield's terminological apparatus is absence of any kind of reflection of the above mentioned distinction between direct and indirect shocks on the one hand, and between static and dynamic systems on the other hand. This lacking reflection results in Setterfield's misleading usage of such terms as "shock", "counter-shock", "transitory shock", "remanence", which is often contradictory and inconsistent.

In Figure 5, there is captured the super-reversible characteristic of a unit-root hysteretic system. At the beginning, the current value of $X$ in time $t\left(X_{t}\right)$ is equal to its equilibrium value $\left(X_{t}^{*}\right)$. Then, the output variable $X$ is affected by a direct shock which increases its current value and, as it is characteristic of a unit-root hysteretic system, also its equilibrium value (because any value of the output variable in this kind of a system is an equilibrium value). After a counter-shock is applied to the system, both the current value and the equilibrium value of the output variable (these two being identical, as a matter of fact, in unit-root hysteretic systems) return to their initial level. The unit-root case exhibits super-reversibility for even though the equilibrium changes down to a shock (a transition between equilibria occurs here), this equilibrium changes only as a result of an exogenous direct shock, though, without any - even short-run - changes in the values of the parameters or functional forms. However, super-reversibility is just a special case of a general reversibility. We define the general reversibility as a case when a shock - countershock sequence 1) results in the final configuration of the current, short-run and long-run 
value being equal to the initial configuration ${ }^{2}$ and 2) may be accompanied by the short-run equilibrium path-dependence (but it does not have to). Then, super-reversibility is a case when a shock - counter-shock sequence 1) results in the final configuration of the current, short-run and long-run value being equal to the initial configuration and 2) is accompanied by absence of path-dependence in the short-run equilibrium.

Figure 5 | Super-Reversibility of the Unit-Root Hysteresis
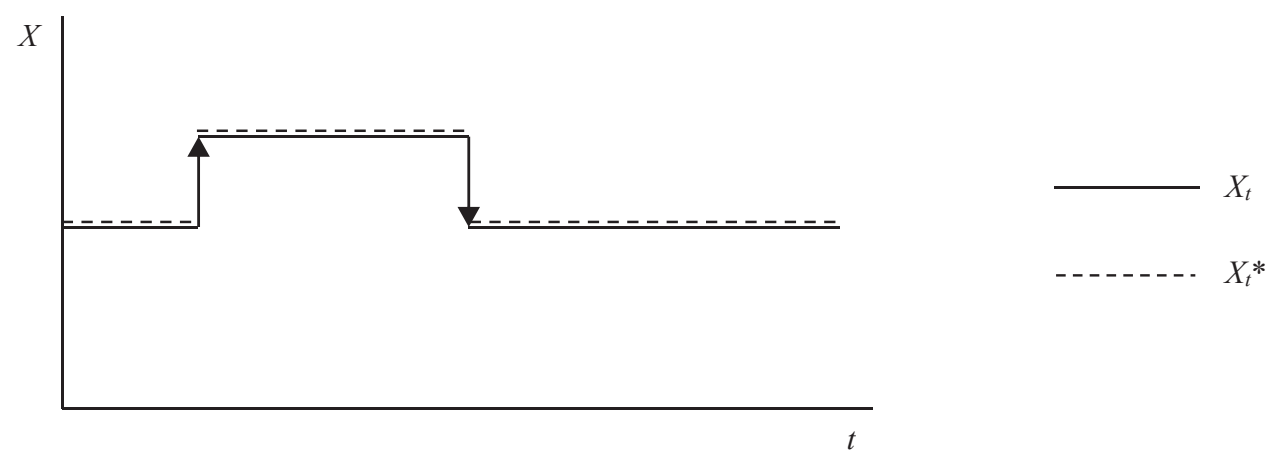

Source: authors' own scheme

Figure 6 | Super-Reversibility in a System of Traditional Equilibrium
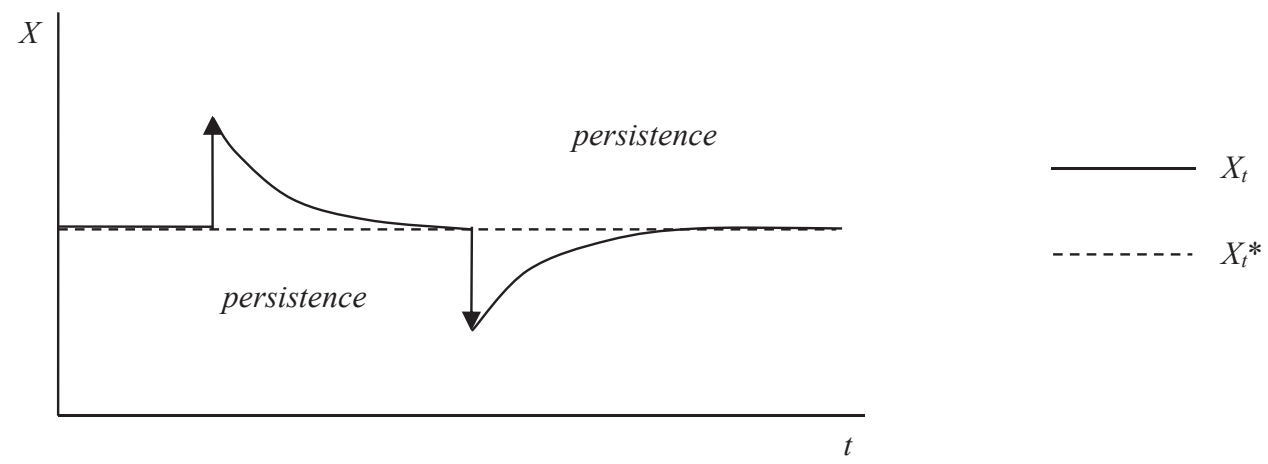

Source: authors' own scheme

As far as the dynamic systems are concerned, traditional-equilibrist systems exhibiting persistence are also super-reversible, according to our definition, because neither the values of parameters, nor the functional forms nor, consequently, the short-run equilibrium undergo any changes following the direct shocks.

In contrast, path-dependent systems displaying either hysteretic persistence or hysteresis may be general-reversible but, on account of their path-dependent nature, they never can be super-reversible because the values of (endogenized) parameters or even the functional forms undergo changes here and, through this mediation, also the equilibrium values undergo changes - may it be in the short run or in the long run or both.

2 In the opposite case, it would be irreversibility. 


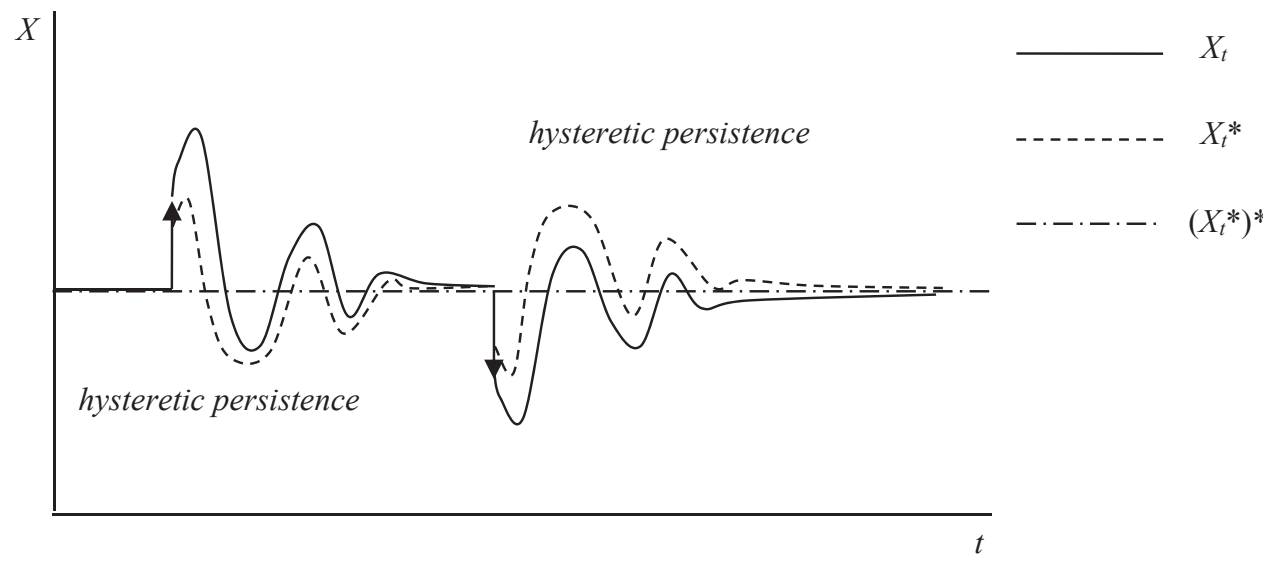

Source: authors' own scheme

In the Figure 7, the initial situation is the equality of the current value, short-run equilibrium value and long-run equilibrium value of $X$. Then, a direct shock increases the current value of $X$ above the long-run equilibrium level and since the short-run equilibrium value of $X$ is path-dependent on the current value of $X$, the short-short run equilibrium value of $X$ (beginning in the following period) is also deviated from the long-run equilibrium level. After some time, the process of convergence restores both the current value and the short-run equilibrium value of $X$ to the initial long-run equilibrium level. Then, a countershock affects the system which deviates the current value of $X$ in the opposite direction to the initial shock.

In the Figure 8, the initial and final equality of the current and short-run and longrun equilibrium values is also present but as long as the counter-shock is not applied, the long-run (and short-run) equilibrium value is different from the initial one, which means hysteresis.

\section{Figure 8 | General Reversibility of Hysteresis}

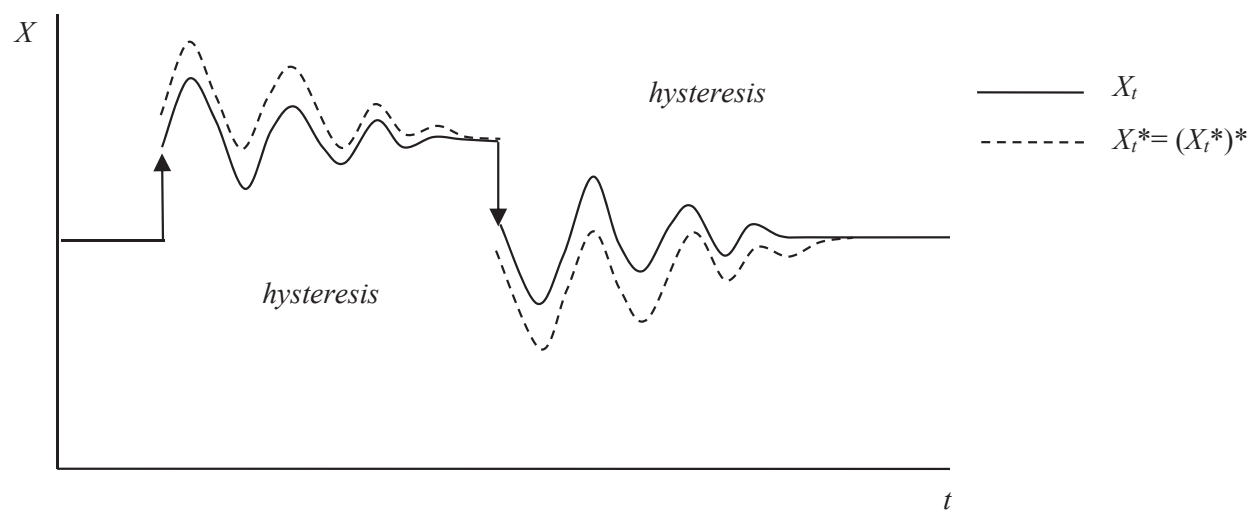

Source: authors' own scheme 
Further on, we distinguish (Chytil, Máslo, 2014, pp. 163-170) among irreversibility of "true" hysteresis (which is irrelevant for systems with direct shocks, though), quasiirreversibility (arising as a result of indirect shocks in dynamic systems) and direct irreversibility (with irreversibility of "Lavoie's" hysteresis as a particular type of direct irreversibility), from which types we may further distinguish (Chytil, Máslo, 2015, p. 16) irreversibility of Setterfield's hysteresis. Setterfield's hysteresis is characterized in terms of deep endogeneity of parameters and adjustment asymmetries (see below), while in "Lavoie's" hysteresis these effects are absent - even though the latter exhibits irreversibility, too, by virtue of the presence of threshold effects in the output variables. "Lavoie's" hysteresis (Chytil, Máslo, 2015, p. 9ff) arises in dynamic systems with direct shocks and threshold effects in the output variable which produce direct irreversibility. An example of "Lavoie's" hysteresis is amended NC model with a horizontal segment of PC which is presented in Lavoie (2008, p. 9).

\section{Figure 9 | Irreversibility of Setterfield's Hysteresis, Scenario 1}

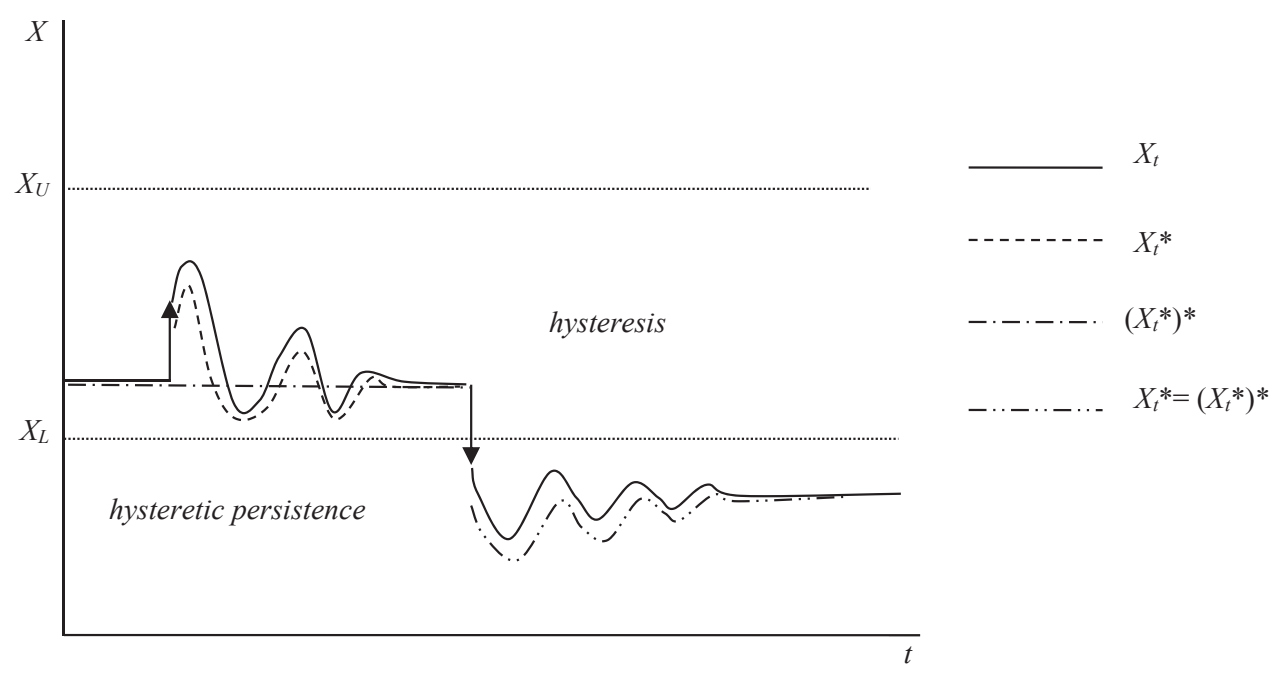

Source: authors' own scheme

Path-dependent systems displaying hysteresis may be irreversible when, for example, an initial direct shock entails crossing the upper threshold ${ }^{3}$ and causes hysteresis (i.e. a change in the long-run equilibrium value of the output variable) but a subsequent application of a counter-shock (same value, opposite sign) does not result in crossing the lower threshold (and, at the same time, the adjustment dynamics does not cause a repeated crossing of the upper threshold). Such a system only exhibits hysteretic persistence and gets restored back to its after-shock long-run equilibrium value of the output variable. Neither dynamic systems of traditional equilibrium, nor unit-root hysteretic models can be irreversible, by definition, because super-reversibility is a defining characteristic thereof.

3 This crossing activates Setterfield's condition (c) described by the equation (33) in the next Subsection 3.3. 


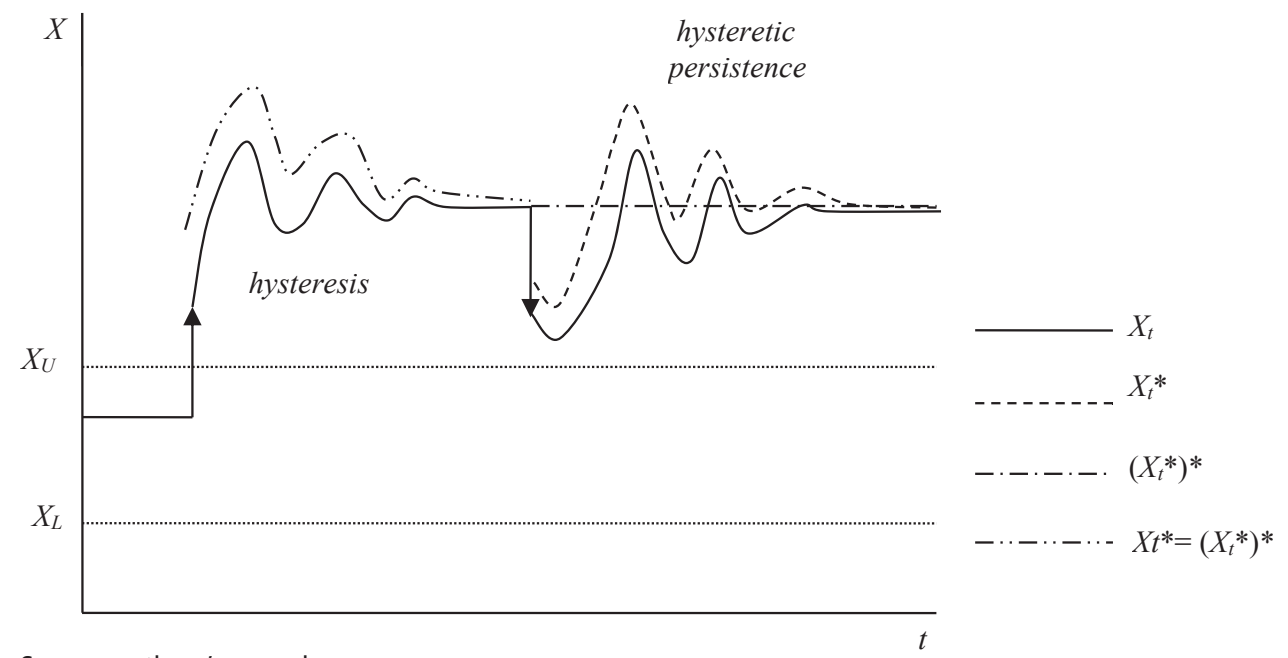

Source: authors' own scheme

\subsection{Deep Endogeneity and Adjustment Asymmetries}

Setterfield (1998a) suggests to build historical time into economic models in a form of the so called deep endogeneity of parameters, i.e. via path-dependent endogenization of parameters. Let us have a model of natural rate of unemployment (Setterfield, 2008)

$$
\begin{gathered}
U_{n}=g(Z) \\
Z_{t}=h_{t}\left(U_{t-1}\right),
\end{gathered}
$$

where the natural rate of unemployment $\left(U_{n}\right)$ is a function of the subjects' willingness to look for a job $(Z)$ and this willingness in a period $t$ is a function of the unemployment rate in the preceding period $\left(U_{t-1}\right)$, where the functional form $(h)$ itself is time-variant. Setterfield refers to this deep endogeneity of the "alleged exogenous" parameter $Z$ as a condition (a)

$$
\text { (a) } h_{t}\left(U_{t-1}\right) \neq 0
$$

that is, the parameter $Z$ in a period $t$ is a function of the unemployment rate in the preceding period. The value of the output variable $U$ undergoes a change following a direct shock and, afterwards, it restores its pre-shock level, either on its own (through a mediation of a convergent process which is present in traditional-equilibrist systems), or as a consequence of an application of a counter-shock. Further on, Setterfield introduces an equation of the so called cumulative neutrality

$$
D U=\sum_{t=1}^{n} d U_{t}=0
$$

The symbol $d U_{t}$ stands for a time derivative or time differentiation, it depends on whether we assume a continuous or rather a discrete case. In this case (Figures 11, 12, 13), we assumed a discrete case. The interpretation of the Equation 31 and Figure 11 is simple: 
a sum of all time differences must give a zero in the end. If the value of a variable is reduced by $\left(U_{2}-U_{1}\right)$ and then the value is increased by subsequent small increments, the sum of the increments must be equal to the opposite value of the initial reduction or, which is the same, the sum of the initial reduction and all the subsequent increments must be equal to zero, in the end.

Figure 11 | Restoring of the Value of the Output Variable to Its Initial Level

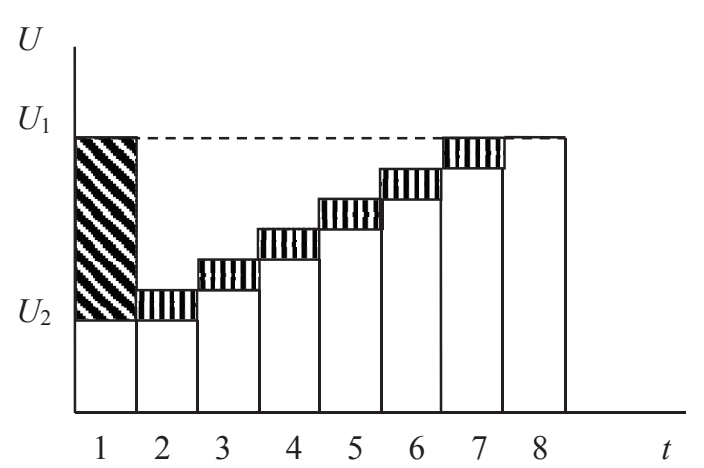

$$
\begin{aligned}
\left(U_{2}-U_{1}\right) & \left(U_{3}-U_{2}\right)+\left(U_{4}-U_{3}\right)+ \\
& +\ldots+\left(U_{8}-U_{7}\right)
\end{aligned}
$$
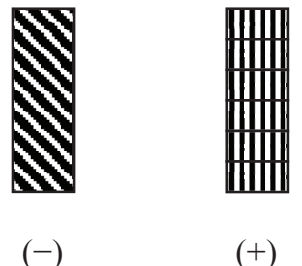

$(-)$

$(+)$

Source: authors' own scheme

If the cumulated effect of these changes in the value of the output variable $U$ to the value of the parameter $Z$ is zero, then

$$
\text { (b) } D Z=\sum_{t=1}^{n} h_{t+1}\left(d U_{t}\right)=0
$$

that is, the initial and final value of the parameter $Z$ are identical which implies that the natural rate of unemployment $U_{n}$ (which is determined by the parameter $Z$ ) at the beginning of the adjustment process is identical with $U_{n}$ at its end $\left(U_{n}^{L R}\right)$, even though its value undergoes short-run changes $\left(U_{n}^{S R}\right)$. The Figure 12 differs from the preceding Figure 11 by the deep endogeneity of the parameter $Z$. The point is that as soon as the current value of $U$ returns to its initial level, the current value of the parameter $Z$ returns to its initial position, too, and because the current value of the parameter $Z$ determines both the short-run and the long-run equilibrium values of $U$, both the short-run and long-run equilibrium values are also equal to the initial short-run and long-run equilibrium level.

In contrast, if the cumulated effect of the changes in $U$ to the parameter $Z$ is non-zero, then a condition (c) holds true

$$
\text { (c) } D Z=\sum_{t=1}^{n} h_{t+1}\left(d U_{t}\right) \neq 0 \text {, }
$$

and so, when the value of $U$ restores its initial level, the value of the parameter $Z$ is different $\left(Z^{* *}\right)$ from the initial one $\left(Z^{*}\right)$. With regard to the fact that the value of $Z$ determines the equilibrium value of $U$, i.e. $U_{n}$, then, as a consequence, the natural rate $U_{n}$ must also be different at the end of this adjustment process $\left(U_{n}^{L R}{ }_{t=9}\right)$ from its initial level $\left(U_{n}^{L R}{ }_{t=1}\right)$. 
Figure 12 | Setterfield's Condition (b)
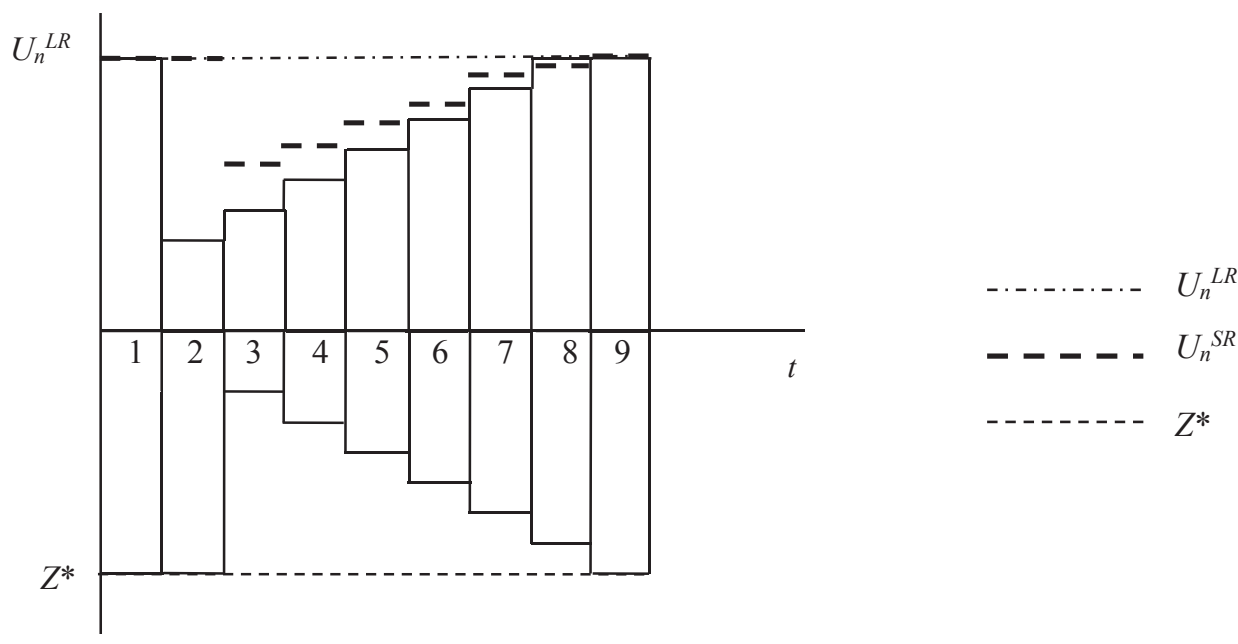

Source: authors' own scheme

Figure 13 | Setterfield's Condition (c)
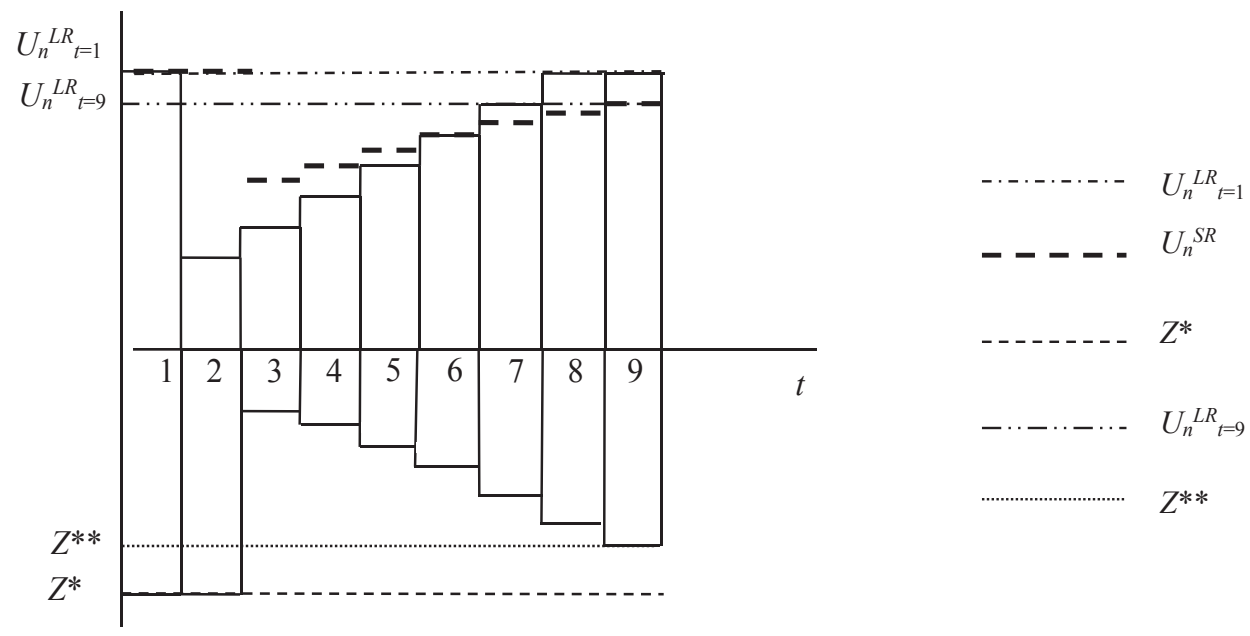

Source: authors' own scheme

In the Figure 13, as distinguished from the previous Figure 12, a return of the current value of $U$ to its initial level does not result in a return of the current value of the parameter $Z$ to its initial level. However, since the current value of the parameter $Z$ determines both the short-run and long-run equilibrium values of $U$, a different final value of the parameter $Z\left(Z^{* *}\right.$ in $\left.t=9\right)$ from its initial value $\left(Z^{*}\right.$ in $\left.t=1\right)$ must result in both different final shortrun and long-run equilibrium values of $U\left(U_{n}^{S R}\right.$ in $t=9$ and $U_{n}{ }_{n}{ }_{t=9}$, respectively) from their 
respective initial values $\left(U_{n}^{S R}\right.$ in $t=1$ and $\left.U_{n}^{L R}{ }_{t=1}\right)$. This is the substance of cumulative nonneutrality described by the Equation 33.

So, Setterfield's hysteresis necessitates not only presence of path-dependence in the short-run equilibrium but also path-dependence in the long-run equilibrium and, on top of that, the path-dependence needs to be caused by deep endogeneity of parameters - i.e. condition (a) - and it has to exhibit adjustment asymmetries - i.e. condition (c). A trigger which activates condition (c) can be e.g. crossing a threshold value (Setterfield, 2008, pp. 23-24) such as depicted in Figures 10 and 11.

The Table 1 presents a classification of the main types of systems according to their respective degree of "historicity" with respect to the 6 attributes of "high-level" historical time, i.e. 1) short-run path-dependence in the output variable, 2) long-run path-dependence in the output variable, 3) path-dependence in the parameters (deep endogeneity of parameters): Setterfield's condition (a), 4) path-dependence in the parameters (adjustment asymmetries): Setterfield's condition (c), 5) irreversibility, 6) irrevocability. The more of these attributes of historical time a system displays, the more "historical" such a system is. Along this line, we scale the systems from those least "historical" on the left to those most "historical" on the right. Only the "high-level" historical time has all 6 attributes, then.

Table 1 | Historical Time Conceptualization Scale

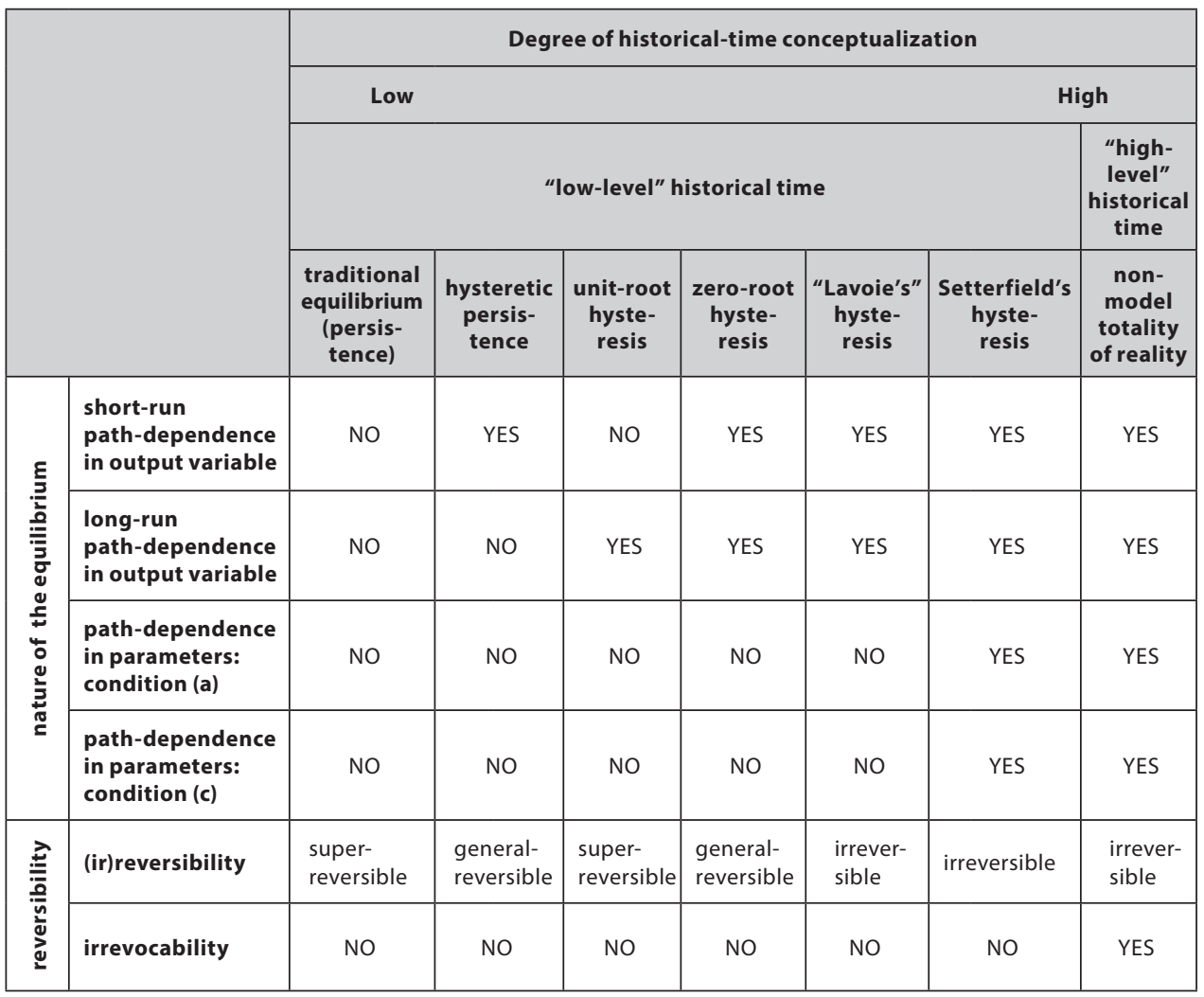

Source: authors' own table 


\section{Model Applications}

\subsection{NC Model and Lavoie's PKA Model}

Monetary policy of the New Consensus is based on the neoclassical foundations of traditional equilibrium and in its simplified version it may be formalized by a three-equation model ISPC-MR. Its dynamic ${ }^{4}$ version (Lavoie, 2008) consists of the following equations:

$$
\begin{aligned}
& \text { IS } \quad \Delta u=-b \cdot \Delta f, \\
& \text { PC } \quad \Delta \Pi=\gamma\left(u-u_{n}\right)+\varepsilon \\
& \text { RF } \quad \Delta f=\alpha\left(\Pi-\Pi^{T}\right)+\beta\left(u-u_{n}\right) .
\end{aligned}
$$

The first equation represents the IS curve which expresses a negative dependence of the absolute change in the capacities utilization rate $(u)$ on the absolute change in the interest rate $(f)$. The second equation describes the Phillips curve which stands for a positive dependence of the absolute change in the inflation rate $\Pi$ on the gap in capacities utilization $\left(u-u_{n}\right)$. The third equation which closes the system is the so called reaction function of the central bank (or the monetary rule, MR) which takes a form of the Taylor rule, according to which the central bank reacts by an adjustment in the interest rate $f$ to any deviation of the inflation rate $\Pi$ from its target $\Pi^{T}$ and/or to any deviation of the capacities utilization rate $u$ from its natural level $u_{n}$. We may define the equilibrium of this system as follows

$$
\left[(\Delta u=0)<==>\left(\Pi=\Pi^{T}\right) \cap\left(u=u_{n}\right)\right] \cap\left[(\Delta \Pi=0)<==>\left(u=u_{n}\right)\right],
$$

whereby, this system has a stable and unique equilibrium.

As a matter of fact, as Lavoie (2006, pp. 176-177) points out, the NC model rests on a tacit but implicitly inherent assumption which Lavoie calls "missing equation of the New Consensus":

$$
g_{n}=g_{n 0}-\mu|\Pi|
$$

where $\mu=0$ for

$$
\mu>0 \text { for } \quad(\Pi>\lambda) U(\Pi<0) \text {, }
$$

or, the natural rate of growth $g_{n}$ (which is an alternative indicator to the capacities utilization rate $^{5}$ ) at a constant level $g_{n 0}$ is compatible with any inflation rate within a certain interval $(0 ; \lambda)$ but the rate $g_{n}$ is a negative function of the absolute value of the inflation rate outside of this interval. In contrast, Lavoie (2008, pp. 12-13) suggests a model amendment to incorporate the influence of demand factors on the natural rate of growth:

$$
\begin{aligned}
& \text { IS } \quad \Delta g=-b \cdot \Delta f \\
& \text { PC } \quad \Delta \Pi=\gamma\left(g-g_{n}\right)+\varepsilon
\end{aligned}
$$

4 Here, the word "dynamic" is used in a meaning different from the meaning presented in Subsection 3.2. At this place, it refers to a system of difference equations.

5 For discussion on a definition of the output gap see Kriesler, Lavoie, 2007, pp. 393-395. 


$$
\begin{aligned}
& \text { RF } \quad \Delta f=\alpha \cdot \Delta \Pi \\
& \text { PKA } \Delta g_{n}=\varphi\left(g-g_{n}\right) .
\end{aligned}
$$

What Lavoie suggests is thus to build path-dependence in the natural growth rate into the NC model through the equation PKA (Post Keynesian Amendment). The newly created system, unlike the original $\mathrm{NC}$ model, does not have a unique and stable equilibrium anymore and it exhibits a continuum of locally stable multiple equilibria, i.e. it presents a zero-root case (one of the characteristic roots of the parameter matrix is zero). Equilibrium of such a system may be characterized as

$$
\Delta g=0 \Longleftrightarrow \Delta g_{n}=0 \Longleftrightarrow \Delta \Pi=0 \Longleftrightarrow \Delta f=0 .
$$

Let us swing the system out of its initial equilibrium configuration by lowering the inflation target to 0.02 and let us examine how this system (for chosen values of parameters and initial equilibrium) will react $^{6}$ :

Table 2 | Chosen Values of Parameters and Constants in a PKA Model

\begin{tabular}{|c|c|}
\hline \multicolumn{2}{|c|}{ Parameters } \\
\hline$a$ & 0.5 \\
\hline$\gamma$ & 0.5 \\
\hline$b$ & 0.5 \\
\hline$\varepsilon$ & 0 \\
\hline$\varphi$ & 0.5 \\
\hline \multicolumn{2}{|c|}{ Constants } \\
\hline$\pi^{\top}{ }_{1}$ & 0.04 \\
\hline$\pi^{\top}{ }_{2}$ & 0.02 \\
\hline$g_{n}$ & 0.05 \\
\hline
\end{tabular}

Source: authors' own table

The diagrams are indicating that lowering the inflation target caused decrease in the natural rate of growth. This implies non-neutrality of the monetary policy not only in the short-run (as the classical dichotomy principle states) but even in the long run, as well. With respect to the determinant and the trace of the matrix of coefficients, this system should exhibit non-uniqueness of equilibrium. So, let us examine the effects of lowering the target to 0.03 , for a change:

$6 \quad$ We used Microsoft Excel to do the sensitivity analysis. We created 4 basic inter-related functions (RF, IS, PC, PKA) in their respective first-difference forms (which is the only way to treat dynamic phenomena in Excel) with the initial values of variables set at their respective equilibrium levels determined by the chosen values of parameters, i.e. $g=g_{n}=0.5 ; \Pi=\Pi_{1}^{\mathrm{T}}=0.04 ; f=f_{0}=f_{n}=\left(a-g_{n}\right) / b=0.1$. In time $t=10$, we let the exogenous shock of inflation target decrease affect the system. 
Figure 14, 15 | Time Diagrams of a PKA Model: Lowering the Inflation Target from 0.04 to 0.02
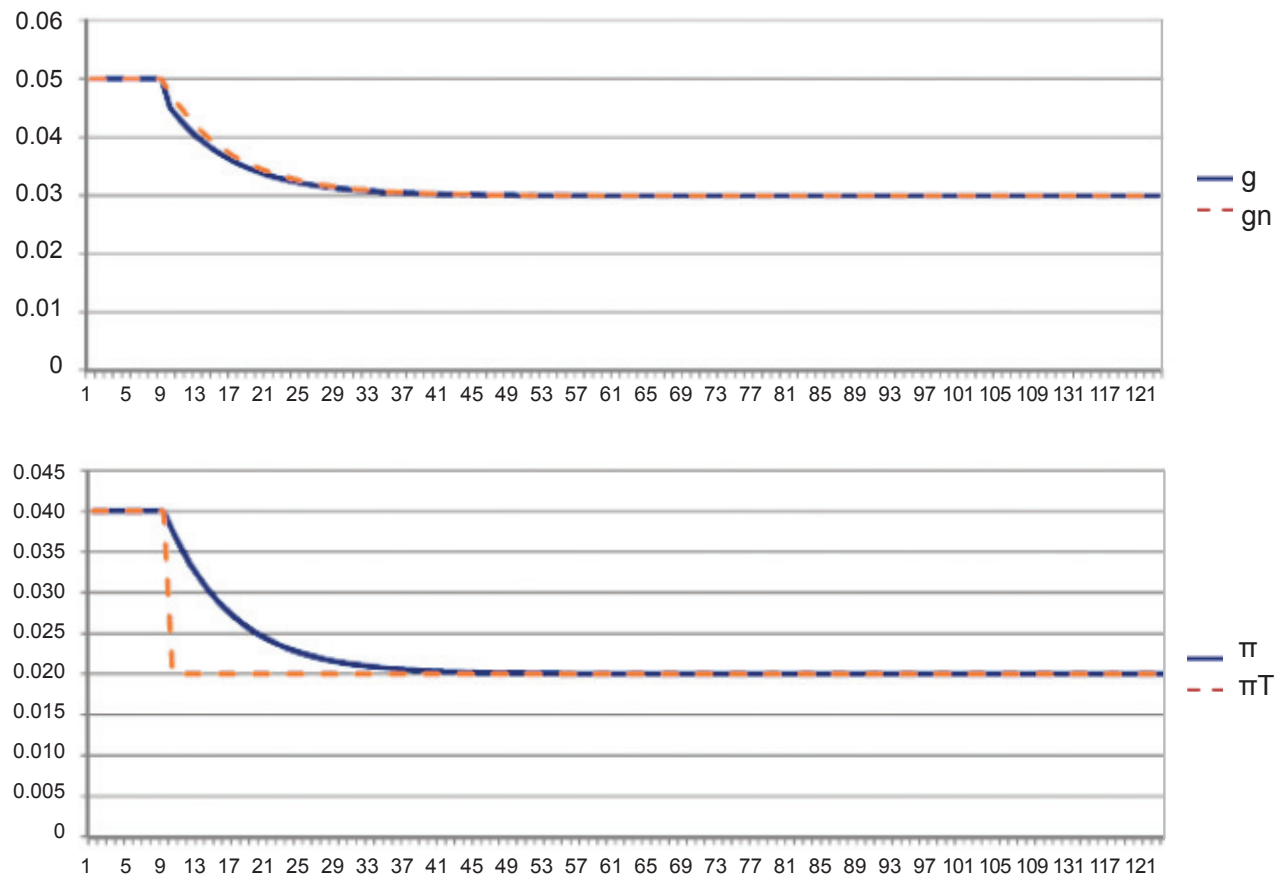

Source: authors' own diagrams

Figures 16 and 17 | Time Diagrams of a PKA Model: Lowering the Inflation Target from 0.04 to 0.03
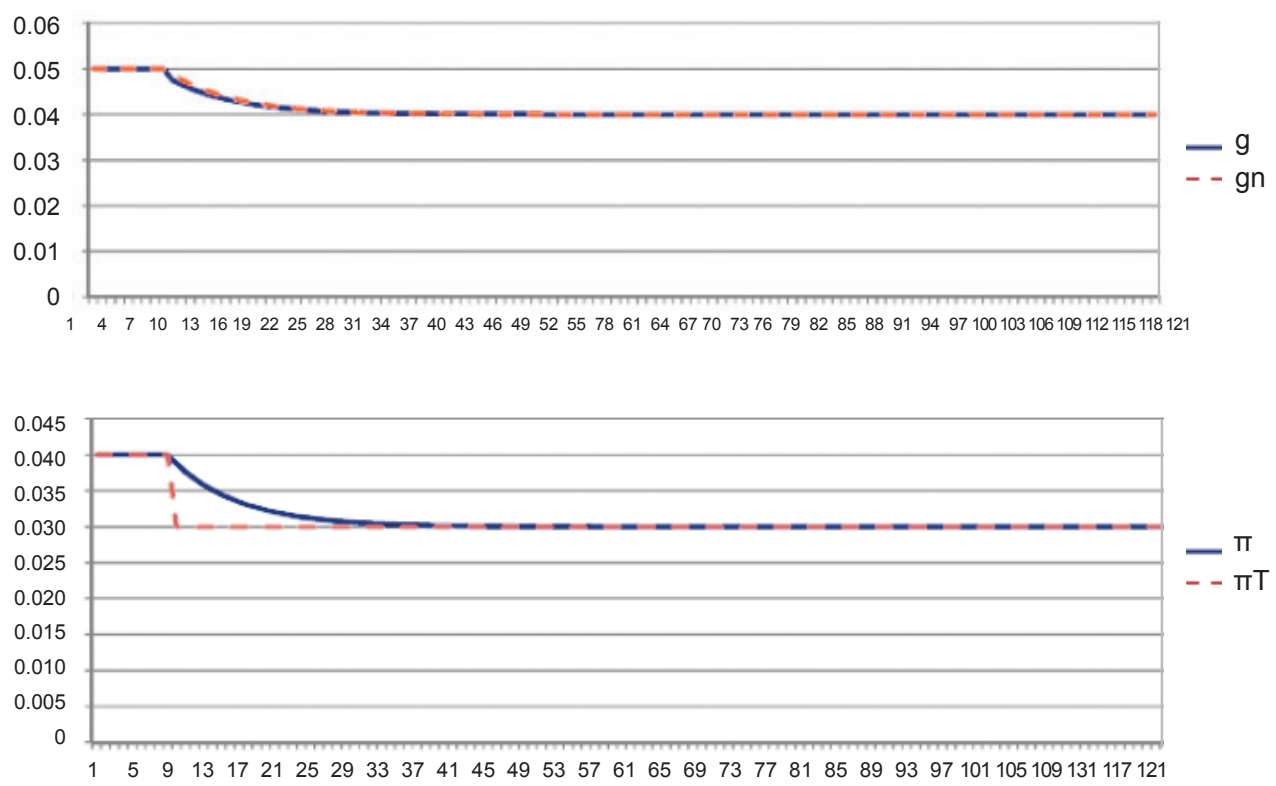

Source: authors' own diagrams 
We can see that a decrease in the natural growth rate is smaller after the lowering of the inflation target. Let us try lowering the target down to zero, then, and we will see the long-run effects:

Figure 18, 19 | Time Diagrams of a PKA Model: Lowering the Inflation Target from 0.04 to 0.00
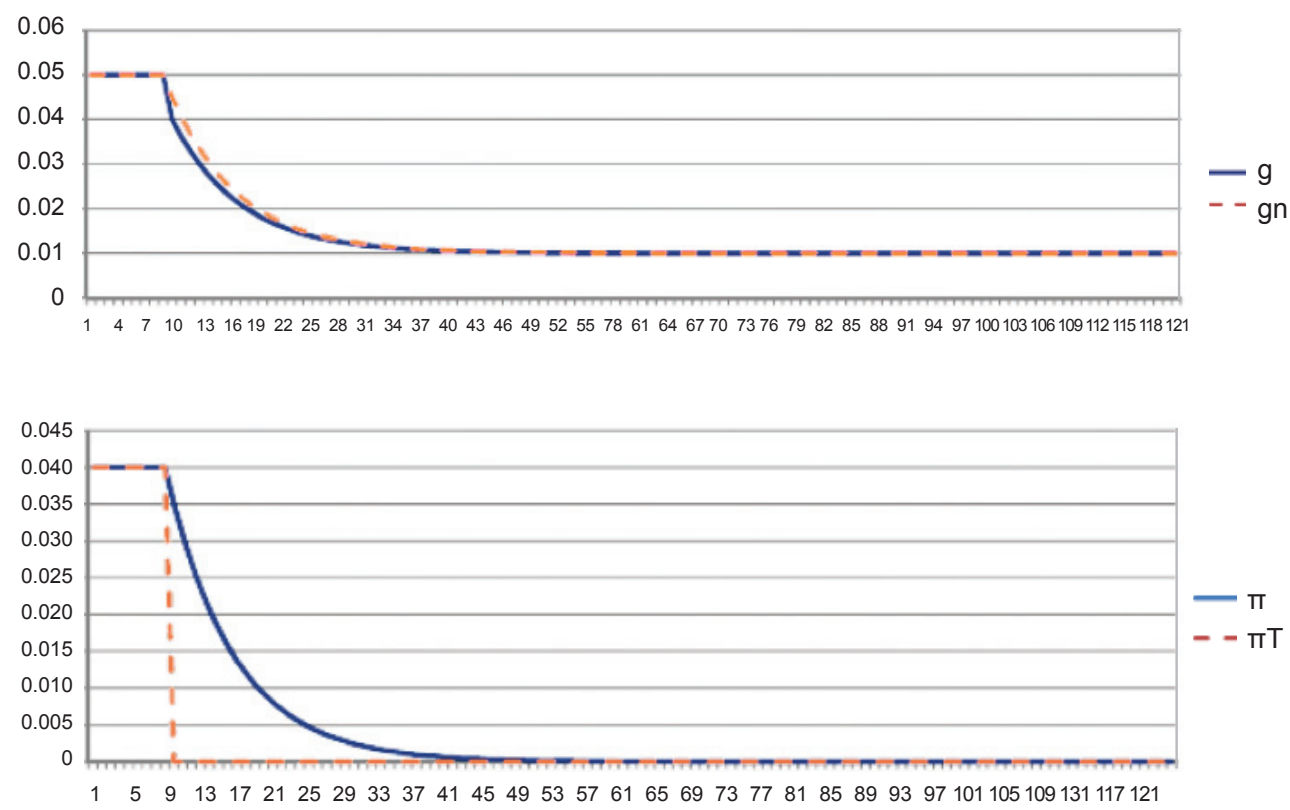

Source: authors' own diagrams

The natural rate of growth fell down to 1 per cent after lowering the inflation target to zero (for the chosen parameter values and the initial equilibrium).

\subsection{Hysteretic Persistence in Lavoie's PKA Model}

We introduced a term hysteretic persistence in the theoretical part of this paper to describe a phenomenon when a natural (equilibrium) value of an output variable is path-dependent in the short-run but it restores its initial level in the long run. Let us demonstrate this case on the example of Lavoie's PKA model (Lavoie, 2006). The system consists of the equations of IS, PC, RF and the PKA equation which incorporates path-dependence in the natural rate and, additionally, an equation of the natural interest rate $^{7}$ (Lavoie, 2006, p. 182):

$$
\begin{aligned}
& \text { IS } \quad g=g_{0}-\beta r+\varepsilon_{1} \\
& \text { PC } \quad d \Pi / d t=\gamma\left(g-g_{n}\right)+\varepsilon_{2}
\end{aligned}
$$

$7 \quad$ Unlike the PKA model in Lavoie (2008) where the interest rate is represented by a symbol $f$, Lavoie (2006) uses the symbol $r$ for it. 


$$
\begin{array}{ll}
\mathrm{RF} & r=r_{0}-\alpha_{1}\left(\Pi-\Pi^{T}\right)+\alpha_{2}\left(g-g_{n}{ }^{e}\right) \\
r_{0}=r_{n}{ }^{T}=\left(g_{0}-g_{n}\right) / \beta
\end{array}
$$

$$
\text { PKA } \quad d g_{n} / d t=\Phi\left(g-g_{n}\right)+\varepsilon_{3}
$$

The variable $g_{n}{ }^{e}$ represents the central bank's estimation of the natural growth rate, $r_{0}$ is the central bank's estimation of the natural interest rate, $r_{n}{ }^{T}$ is the natural interest rate. The equality $r_{0}=r_{n}{ }^{T}=\left(g_{0}-g_{n}\right) / \beta$ can be derived from the AD equation in the state of equilibrium. ${ }^{8}$ The equilibrium conditions have to be

$$
(d g / d t=0) \cap\left(d g_{n} / d t=0\right) \cap(d \Pi / d t=0) \cap\left(r=r_{0}=r_{n}^{T}\right) .
$$

Let us examine the inner causal structure of this model after a transitory demand shock is applied:

\section{Figure 20 | Causal Sequence in a PKA Model Following a Transitory Demand Shock}

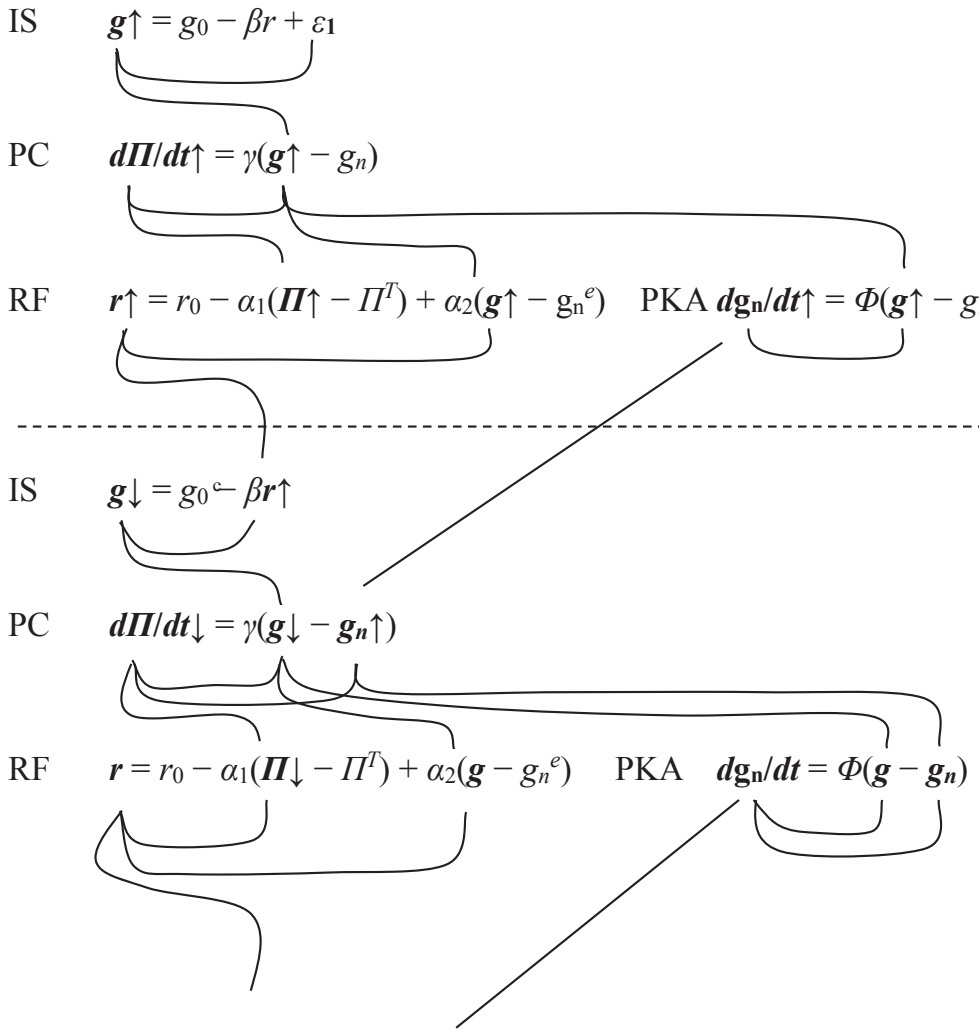

Source: authors' own scheme

$8 \quad$ See Lavoie, 2006, pp. 169, 174. 
Let us choose following values of parameters and let us examine the effects of a transitory demand shock:

Table 3 | Chosen Values of Parameters and Constants in a PKA Model

\begin{tabular}{|l|c|}
\hline \multicolumn{1}{|c|}{ parameters } & \\
\hline$a_{1}$ & 0.5 \\
\hline$a_{2}$ & 0.5 \\
\hline$\beta$ & 0.5 \\
\hline$\gamma$ & 0.5 \\
\hline$\varphi$ & 0.5 \\
\hline$g_{0}$ & 0.05 \\
\hline$g_{n}{ }^{e}$ & 0.05 \\
\hline$g_{0}$ & 0.065 \\
\hline$r_{01}$ & 0.03 \\
\hline$\varepsilon_{1}$ (temp.) & 0.02 \\
\hline & \\
\hline constants & \\
\hline$\pi^{\top}{ }_{1}$ & 0.04 \\
\hline$g_{n 1}$ & 0.05 \\
\hline$r_{n}{ }^{\top}{ }_{1}$ & 0.03 \\
\hline
\end{tabular}

Source: authors' own table

The natural growth rate exhibits hysteretic persistence - even though the natural growth rate is a function of the value of the current growth rate of the preceding period in the short run, it is determined exogenously in the long run, nonetheless. To summarize it, Lavoie's PKA model displays hysteretic persistence in consequence of a temporary demand shock and, in effect, general reversibility (but not super-reversibility). This model does not display deep endogeneity in any parameter and, therefore, it does not satisfy the necessary condition of Setterfield's hysteresis, i.e. condition (a), and, therefore, it cannot satisfy the sufficient condition of Setterfield's hysteresis, i.e. condition (c), either. Due to the absence of path-dependence in the long-run equilibrium, the conceptualization of historical time is at a lower level in this model, in comparison to unit- and zero-root hysteresis. However, by virtue of the incorporation of path-dependence in the short-run equilibrium, hysteretic persistence finds itself to the right from the traditional-equilibrist systems on the historicaltime conceptualization scale because the systems of traditional equilibrium only display persistence. 
Figures 21, 22 and 23 | Time Diagrams of a PKA Model: Hysteretic Persistence Resulting from a Transitory Demand Shock
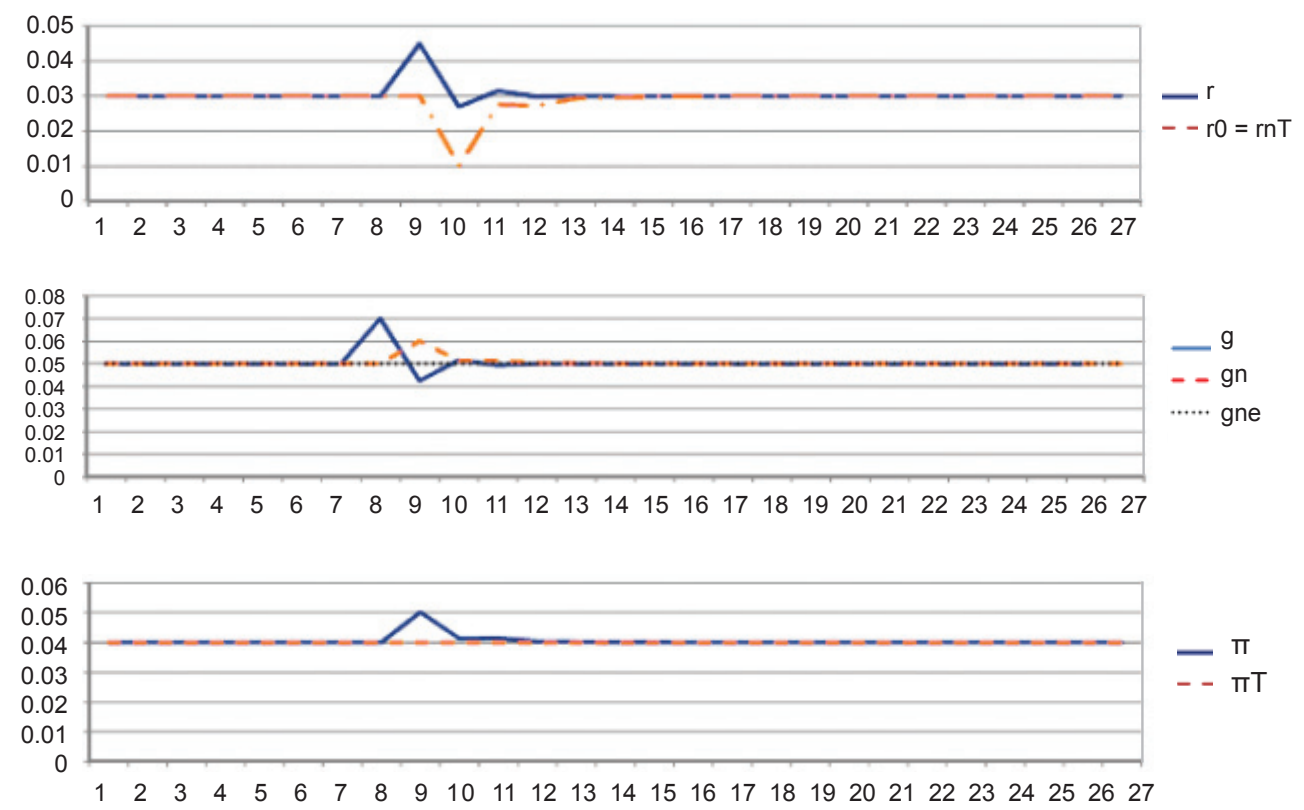

Source: authors' own diagrams

\section{Conclusion}

We set a threefold goal in this paper: to fill up a notional hole existing in the research field of the nature of equilibrium ("path-dependence" " "path-independence"); to suggest a remedy in the research field of system reversibility ("reversibility"/"irreversibility"); and to provide a characterization of historical time based on attributes determined by these characteristics to suggest a conceptualization scale which would make it possible to assess various systems with respect to their respective degree of "historicity".

As for the first goal, in the realm of research into path-dependence of equilibrium, our contribution consists in extension of the cases of persistence (traditional equilibrium) and hysteresis by the case that we call hysteretic persistence which has not yet been properly treated in the existing literature. We defined hysteretic persistence by presence of pathdependence in the short-run equilibrium. We regarded as necessary to introduce this new notion because a phenomenon of path-dependence in the short-run equilibrium cannot be described by either of the existing notions, i.e. hysteresis (which refers to path-dependence in the long-run equilibrium) and persistence (path-independence in both the short-run and long-run equilibrium).

As for the second goal, we extended our previous criticisms towards Setterfield's (1995, 1996, 1998a, 2008) chaotic terminology, which we provided in Chytil, Máslo (2014, 2015) by suggesting a definition of general reversibility as such a case when a shock - countershock sequence 1) results in the final configuration of the current, short-run and long-run value being equal to the initial configuration and 2) may be accompanied by the shortrun equilibrium path-dependence (but it does not have to). According to our terminology, 
general reversibility (in opposition to Setterfield, 2008) includes super-reversibility as a special case that we characterize as such a case when a shock - counter-shock sequence 1) results in the final configuration of the current, short-run and long-run value being equal to the initial configuration and 2) is accompanied by absence of path-dependence in the short-run equilibrium (so, for example the cases of unit-root hysteresis and persistence). We hold it as necessary to introduce the notion of general reversibility because such phenomena as a shock - countershock sequence in hysteretic-persistent and hysteretic systems cannot be described by either of the existing notions, i.e. super-reversibility (which rules out presence of path-dependence in the short-run equilibrium) and irreversibility (which results in the final configuration of the current, short-run and long-run value being different from the initial configuration).

As for the third goal, our view on the conceptualization of historical time drew upon Setterfield's (1998b) distinction between a higher and lower level of historical time. What we did was replacing Setterfield's only too general dichotomy by our conceptualization scale based on our identifying 6 attributes of "high-level" historical time: 1) pathdependence in the short-run equilibrium, 2) path-dependence in the long-run equilibrium, 3 ) deep endogeneity of parameters (condition (a)), 4) adjustment asymmetries (Setterfield's hysteresis, condition (c)), 5) irreversibility, 6) irrevocability. Having this scale at hand, we are able to assess a degree of "historicity" of any system with regard to such system's compliance with as many of the 6 attributes as possible.

In the model section, practical application of our concept of hysteretic persistence was demonstrated on an example of Lavoie's PKA model (Lavoie, 2006) affected by a transitory demand shock. Setting the hysteretic persistence of Lavoie's PKA model into our conceptualization scale, we drew following conclusions about a degree of this system's "historicity": 1) due to the absence of path-dependence in the long-run equilibrium, the conceptualization of historical time in this model is at a lower level, in comparison to unit- and zero-root hysteresis (i.e. it has a lower degree of "historicity" than the unit- and zero-root hysteretic systems); 2) by virtue of the incorporation of path-dependence in the short-run equilibrium, hysteretic persistence finds itself to the right from the traditionalequilibrist systems on the historical-time conceptualization scale (i.e. it has a higher degree of "historicity" than traditional equilibrist systems) because the systems of traditional equilibrium only display persistence.

\section{References}

Amable, B., Henry, J., Lordon, F., Topol, R. (1993). Unit-Root In the Wage-Price Spiral Is Not Hysteresis In Unemployment. Journal of Economic Studies, 20(1/2), 123-135, https://doi.org/10.1108/01443589310038551

Amable, B., Henry, J., Lordon, F., Topol, R. (1994). Strong Hysteresis versus Zero-Root Dynamics. Economic Letters, 44(1-2), 43-47, https://doi.org/10.1016/0165-1765(93)00300-d

Franz, W. (1990). Hysteresis in Economic Relationships: An Overview. Empirical Economics, 15(2), 109-125, https://doi.org/10.1007/bf01973448

Hayek, F. A. (1955). Degrees of Explanation. The British Journal for the Philosophy of Science, 6(23), 209-225, https://doi.org/10.1093/bjps/vi.23.209

Chick, V. (2004). On Open Systems. Brazilian Journal of Political Economy, 24(1), 3-16.

Chytil, Z., Máslo, L. (2014). (Ir)reversibility of Hysteretic Systems in Post-Keynesian Economics. International Journal of Social Sciences, III(4), 153-172. Available at: http://www.iises.net/ir-reversibility-of-hysteretic-systems-in-post-keynesian-ec.html 
Chytil, Z., Máslo, L. (2015). Hysteresis in Post-Keynesian Monetary Theory. European Scientific Journal, 11(7), 1-17. Available at: http://eujournal.org/index.php/esj/article/ viewFile/5301/5110

Jespersen, J. (2009). Macroeconomic Methodology. A Post-Keynesian Perspective. Edward Elgar. ISBN 9781845427368.

Kaldor, N. (1934). A Classificatory Note on the Determinateness of Equilibrium. The Review of Economic Studies, 1(2), 122-135, https://doi.org/10.2307/2967618

Kaldor, N. (1972). The Irrelevance of Equilibrium in Economics. The Economic Journal, 82, 1237-1255, https://doi.org/10.2307/2231304

Katzner, D. (1993). Some Notes on the Role of History and the Definition of Hysteresis and Related Concepts In Economic Analysis. Journal of Post Keynesian Economics, 15(3), 323-345, https://doi.org/10.1080/01603477.1993.11489947

Katzner, D. (1999). Hysteresis and the Modeling of Economic Phenomena. Review of Political Economy, 11(2), 171-181, https://doi.org/10.1080/095382599107101

Keynes, J. M. (1936). The General Theory of Employment, Interest and Money. Collected Writings of John Maynard Keynes, Volume VII. Royal Economic Society, Cambridge University Press, 1978. ISBN: 0333107292.

Kriesler, P., Lavoie, M. (2007). The New Consensus on Monetary Policy and Its PostKeynesian Critique. Review of Political Economy, 19(3), 387-404, https://doi. org/10.1080/09538250701453097

Lavoie, M. (2006). A Post-Keynesian Amendment to the New Consensus on Monetary Policy. Metroeconomica, 57(2), 165-192, https://doi.org/10.1111/j.1467-999x.2006.00238.x

Lavoie, M. (2008). Towards Taming the New Consensus: Hystereris and Some Other Post-Keynesian Amendments. ROBINSON Working Paper No. 08-08.

Máslo, L. (2016). Determinismus, Path-dependence a Nejistota Pohledem Postkeynesovske Ekonomie. (Determinism, Path-dependence and Uncertainty: A Post Keynesian Perspective) Dissertation Thesis, University of Economics, Prague. Available at: http:// www.vse.cz/vskp/49149_determinismus_path_dependence_a\%C2\%A0nejistota_ pohledem_postkeynesovske_ekonomie

Máslo, L., Chytil, Z. (2015). Uncertainty, Money and Underemployment. European Scientific Journal, August 2015(Special Edition), 206-224. Available at: http://eujournal.org/index. php/esj/article/viewFile/6153/5937

Setterfield, M. (1995). Historical Time and Economic Theory. Review of Political Economy, 7(1), 1-27, https://doi.org/10.1080/09538259500000001

Setterfield, M. (1996). Hysteresis and Uncertainty: Complementary or Competing Visions of Evolving Economic Systems, in Kosters, S., ed., Interactions in Political Economy: Malvern After Ten Years, London: Routledge, pp. 133-148. ISBN 0-415-13393-9.

Setterfield, M. (1997). Should Economists Dispense with The Notion of Equilibrium? Journal of Post Keynesian Economics, 20(1), 47-76, https://doi.org/10.1080/01603477.1997.11490138

Setterfield, M. (1998a). Adjustment Asymmetries and Hysteresis in Simple Dynamic Models. The Manchester School, 66(3), 283-301, https://doi.org/10.1111/1467-9957.00102

Setterfield, M. (1998b). History versus Equilibrium: Nicholas Kaldor on Historical Time and Economic Theory, Cambridge Journal of Economics, 22(5), 521-537, https://doi. org/10.1093/cje/22.5.521

Setterfield, M. (2008). Path Dependency, Hysteresis and Macroeconomics. Available at: http://citeseerx.ist.psu.edu/viewdoc/download?doi=10.1.1.150.1785\&rep=rep1\&type=pdf 